Aroueología Y SociedAd

№ 26, 2013: 117-130

ISSN: 0254-8062

RECIBIDO: 30 / MAR. / 2013 ACEPTADO: 5 / MAY. / 2013

\title{
EL USO DE REFLECTOGRAFÍA INFRARROJA EN EL REGISTRO DE TATUAJES EN MOMIAS PARACAS-NECRÓPOLIS
}

\author{
PATRICIA MAITA AgURTO \\ Museo Nacional de Aroueología, Antropología e Historia del Perú, Colección de Antropología Física \\ pat_maita@hotmail.com
}

Enma Minaya Cabello

Museo nacional de Aroueología, Antropología e Historia del Perú, Laboratorio Químico enmamin@hotmail.com

\section{RESUMEN}

Una exploración superficial de la piel de un grupo de doce momias Paracas de la Necrópolis de WariKayan, utilizando a la técnica de reflectografía infrarroja ha permitido registrar las modificaciones culturales permanentes de la piel a través de los tatuajes.

La técnica de reflectografía infrarroja es comúnmente usada en el análisis de obras de arte, especialmente cuando se desea observar trazos y diseños ocultos debajo de capas de pintura. Al utilizar la técnica en momias, ha sido posible registrar tatuajes que no son visibles debido a diferentes condiciones.

En muchos casos, el registro de los tatuajes Paracas se ve limitado porque el tratamiento funerario y la mala preservación de los cuerpos encubren los tatuajes, pudiendo ser observados solo como manchas azules o negras en la piel. Los resultandos obtenidos con el uso de la reflectografía infrarroja muestran características de la modificación de la piel que nunca antes han sido registradas, como el patrón de distribución de tatuajes en los cuerpos y diseños que han sido usados en la decoración corporal, los cuales se asemejan con aquellos diseños registrados en la iconografía Paracas de soporte textil y cerámico.

PALABRAS ClAVE: Tatuajes, Paracas, Warikayan, reflectografía infrarroja.

\section{Abstract}

An exploration of the skin of twelve Paracas mummies using infrared reflectorgraphy has permitted the record of permanent cultural changes of the skin by tattoos.

Infrared reflectography is typically used in the analysis of artwork, in particular to discover traces and designs hidden under paint layers. When used in mummies, the technique allows recording hidden tattoos.

In many cases recording Paracas tattoos is difficult because the funerary treatment and bad preservation have camouflage tattoos, which are seem like blue or black stains in the skin. Results show characteristic of the Paracas skin modification that has never been registered before, such as pattern distribution of tattoos in the bodies and designs had been used for corporal decoration.

KEYWORDS: Tattoos, Paracas, Warikayan, infrared reflectorgraphy. 


\section{INTRODUCCIÓN}

Entre 1927 y 1928 el Dr. Julio C. Tello junto a un equipo del Museo de Arqueología Peruana excavaron un cementerio con grandes fardos funerarios en la Península de Paracas, al cual denominaron «Necrópolis de Wari Kayan», sectorizándolo en dos núcleos funerarios A y B. De acuerdo a los tamaños de los fardos y sus ofrendas funerarias asociadas, Tello asignó las categorías X, Y y Z. Según Tello y Mejía (1979), el fardo de categoría X o de 1ํo categoría, contiene el cadáver de un jefe o sacerdote debido a su asociación con suntuosas ofrendas textiles, mientras que un fardo de categoría Y hace referencia al cadáver de un cazador, pescador, agricultor, tejedor, ceramista, guerrero, etc., enterrado con sus ofrendas. Por último, la categoría $\mathrm{Z}$ es un fardo pequeño que contiene el cadáver de un miembro común de la familia o ayllu de Paracas.

En los posteriores años al descubrimiento del cementerio de Wari Kayan, Tello y sus colaboradores desenfardelaron y analizaron varios individuos. El aspecto reseco y negruzco que presentaban las momias los llevó a pensar que la momificación en Wari Kayan consistió en el desecado por ahumado y el uso de una sustancia liquida similar a la brea (Tello y Mejía 1979: 359).

En sus anotaciones del desenfardelamiento de las momia 310, considerada de 1ํo categoría, Tello y Mejía señalan que da «la impresión de haber sido desecado mediante el fuego, aunque no se encuentran huellas de carbonización; sin embargo existen algunas porciones de ceniza en el asiento, mezcladas con el polvo de los tejidos carbonizados [...]. La planta de los pies arqueada con la piel resquebrajada, como si fuera soazada.» (Tello y Mejía 1979: 381). Por su parte, James Vreeland, durante el desenfardelamiento de la momia 226 informa que el cadáver «aparece como si fuera pintado con una sustancia de color azul, a pesar de que pueda ser su color natural de deterioración» (Vreeland 1976).

La momificación ha logrado preservar los cuerpos de Paracas-Necrópolis por varias centurias, sin embargo diversos factores han determinado que actualmente las momias no se encuentren totalmente íntegras, habiéndose perdido principalmente las zonas del tórax y abdomen, por lo que actualmente, en su mayoría, las momias consisten de brazos, manos, piernas, pies y algunas cabezas. Debido a los procesos de momificación y el estado de conservación de los cuerpos, muchos de los tatuajes están ocultos debido a la coloración oscura de las momias y aunque existen casos en que los tatuajes son percibidos fácilmente, varios de ellos logran observarse como manchas de coloraciones azules o negras, por lo que el registro se torna dudoso ante la posibilidad de confundir tatuajes con manchas producidas por el proceso de descomposición del cuerpo.

Debido a la problemática de las momias Paracas y con el objetivo de ensayar nuevas técnicas de análisis de momias que permita el registro y análisis de las modificaciones culturales en la piel, se ha usado un equipo de reflectografía infrarroja para observar los diseños de los tatuajes que permanecen ocultos en las momias Paracas-Necrópolis debido al tratamiento funerario y al mal de estado de conservación que presentan algunas de ellas.

La técnica de reflectografía infrarroja ha permitido definir los diseños de los tatuajes que inicialmente se observaban como manchas, se ha descartado manchas que se presumían como tatuajes y se ha verificado la presencia de tatuajes en cuerpos que a simple vista no los presentaban.

La información que se presenta corresponde a una investigación más amplia llevado a cabo por las autoras desde el año 2011 con los fondos museográficos de la colección de antropología física del Museo Nacional de Arqueología, Antropología e Historia del Perú y el respaldo científico del Laboratorio Químico del MNAAHP.

\section{LA MOdificación CUltural DEL CUERPo en PARACAS}

De acuerdo a trabajos etnográficos es claro que la ornamentación del cuerpo juega un papel importante en la identificación individual y grupal, además que responden a adaptaciones especiales en 
sentido religioso, utilitario, emblemático, jerárquico, de iniciación, etc. (Aufderheide y RodriguezMartin 1998; Brain 1979; Drewal y Thompson 1983; Faris 1972; Field 1958; Handy 1922). Al estudiar las momias Paracas queda muy claro que hubo una práctica muy intensa de modificar culturalmente la apariencia física del individuo, ya sea por medios temporales de ornamentación (pintura corporal, vestidos, peinados) o permanentemente a través de la modificación artificial del cráneo y el tatuaje.

El primer reporte sobre la presencia de tatuajes en momias Paracas-Necrópolis es proporcionado por T.D. Stewart (1943), al describir tatuajes en la momia 234 de Wari Kayan, cuyos diseños aparentemente consistían en pares de puntos sobre brazos y piernas. Tello y Mejía (1979) señalan que el tinte empleado en los tatuajes es de color azul y negro. Basándose principalmente en la observación de momias de primera categoría de Wari Kayan, Tello y Mejía han señalado que el tatuaje es un rasgo cultural de Paracas, siendo los diseños más frecuentes aquellos que corresponden a aves, estrellas y peces, encontrándose generalmente estos en el antebrazo, piernas y tórax, pero nunca en la cara ni en la espalda.

Observaciones recientes por parte de las autoras sobre momias Paracas-Necrópolis, han verificado que sí existen tatuajes en la cara, especialmente en zonas del rostro cercanas a las orejas y sobre las orejas, como se observa en las momias 70 y 81 (Figs. 12 y 13), que se presentan en este trabajo. Posiblemente la existencia de tatuajes en la cara pasó desapercibida para el equipo de Tello, especialmente si estas zonas se encontraban cubiertas con cabello u obscurecidas por la momificación.

Los tatuajes son usados como signo de estatus social, asociado a ritos de pasaje a la adultez o simplemente como una forma de embellecer el cuerpo (Aufderheide y Rodriguez-Martin 1998; Dembo e Imbelloni 1938). Debido a la persistencia de tendencias y estilos en algunas sociedades prehispánicas, los tatuajes han sido utilizados para identificar grupos culturales. Allison et al. (1981) señala que los tatuajes son marcadores de identidad, al observar que historicamente han estado presentes en sociedades costeras, mientras que las poblaciones altoandinas no muestran tales prácticas.

El acto de inscribir diseños permanentemente en el propio cuerpo a través del tatuaje, puede ser considerado como una señal manifiesta de identidad dentro de Paracas-Necrópolis. La práctica a su vez demostraría la clara intención de diferenciarse entre personajes, lo cual es de esperarse especialmente dentro de sociedades con una compleja estratificación social, en las que se busca enfatizar el estatus social (Horowitz 1985; Sorokin 1973).

El estatus estaría reforzado con el uso de marcadores de identidad y prestigio, los cuales se encuentran en gran cantidad en el ajuar funerario de las momias Paracas-Necrópolis, en el que abundan los implementos personales ostentosos. Los cadáveres Paracas, además de estar asociados a mantos textiles altamente ornamentados y cargados de una vasta iconografía, presentan una gran cantidad de adornos personales como diademas, narigueras, brazaletes, orejeras, collares de conchas marinas, penachos, pelucas y llautos, lo que sugiere la importancia de estos elementos como marcadores personales y sociales.

\section{ANÁlisis de TATUAJES}

Los tatuajes son marcas indelebles en la piel, realizados con el uso de agujas que transfieren el pigmento del tatuaje en la epidermis. El uso de diseños como símbolos es universal en todos los grupos humanos, sin embargo, el significado de los tatuajes varía a través de culturas e individuos.

Análisis microanalíticos y de corte transversal de un grupo de cinco muestras de piel tatuada de momias Paracas-Necrópolis, realizados en el año 2011 por las autoras, revelaron que los depósitos de pigmento se hallan en la epidermis, mientras que el espesor de los tatuajes fluctúa entre 50 a $100 \mu \mathrm{m}$. Al examinar los pigmentos al microscopio se observaron partículas suspendidas muy finas en estado amorfo, de 1 a $2 \mu \mathrm{m}$ de diámetro, siendo caracterizadas como negro de carbón (C) en la forma de negro de humo, también conocido como hollín. La mayor parte del pigmento se ha encontrado como 
conglomerado, produciendo el aspecto de pintura bajo la piel. El análisis elemental con fluorescencia de rayos $\mathrm{X}$ resultó apropiado para identificar particularmente impurezas de hierro (Fe), cobre (Cu) y silicio (Si) como partículas constituyen de las sales del pigmento negro de humo.

Con el objetivo de identificar los tatuajes que han sido obscurecidos por el tratamiento funerario, se optó por utilizar un equipo de reflectografía infrarroja. Se escogió al azar una muestra de momias que presentaran por lo menos una de las dos condiciones: a) momias sobre las cuales se había registrado previamente la existencia de tatuajes en algunas zonas corporales, b) momias en las que no se tenía certeza si las manchas sobre la piel correspondían a tatuajes. Las momias analizadas se señalan en la tabla № 1 .

Tabla 1. Momias analizadas, presentadas según el número de fardo asignado por Julio $C$. Tello, sexo estimado y categoría de fardo

\begin{tabular}{ccc} 
Momia & Sexo & $\begin{array}{c}\text { Categoría } \\
\text { (según Tello y Mejía, 1979) }\end{array}$ \\
\hline 12 & F & 1 \\
28 & F & 1 \\
30 & F & 3 \\
70 & F & 3 \\
73 & F & 3 \\
\hline 81 & F & 3 \\
\hline 86 & F & 3 \\
\hline 87 & F & 3 \\
\hline 110 & M & 3 \\
\hline 234 & F & 3 \\
437 & M & 2 \\
\hline 451 & M & 1 \\
\hline
\end{tabular}

La reflectografía infrarroja es una técnica no invasiva que se basa en la obtención de imágenes en el espectro infrarrojo. Desde los años 70 la reflectografía infrarroja viene siendo usada en el análisis histórico y estilístico de pinturas de caballete previo a la conservación y restauración. Cuando la radiación infrarroja penetra en las capas de pintura, las capas superiores no son visibles, por lo que se puede observar trazos, esbozos, dibujos y firmas escondidas en las pinturas (van Asperen De Boer 1976, 1983).

El equipo utilizado en el registro de los tatuajes consta de una cámara de video, una lámpara de radiación infrarroja y un monitor. La radiación infrarroja emitida por la lámpara bloquea el espectro visible, permitiendo que la cámara de video registre la capa subyacente oculta al ojo humano. La imagen es emitida en blanco y negro por el monitor y desde la pantalla se capta la imagen mediante fotografía digital. Uno de los problemas con el equipo es que al captar imágenes del monitor, las fotografías pueden presentarse borrosas y con desenfoque, por lo que es necesario realizar varias tomas fotográficas con diferentes tiempos de exposición y diafragma cerrado para lograr mayor profundidad de campo y mejorar la calidad de las imágenes.

\section{TAtuajes Paracas: Diseños y distribución en el CUeRPo}

La reflectografía infrarroja ha permitido reconocer la ubicación y orientación de los tatuajes, además de aproximarnos a los posibles diseños de los tatuajes. Es necesario resaltar que la reflectografía infrarroja registra la capa profunda que no es visible al ojo, por lo que la imagen que proyecta corresponde a la forma de la dispersión del pigmento del tatuaje en la epidermis. El diseño del ta- 
tuaje que se encuentra sobre la piel no puede ser visto detalladamente al encontrarse en superficie y oscurecido por el tratamiento funerario (Figs. 1, 3, 5 y 7), pero al aplicar la radiación infrarroja es posible captar las imágenes de los tatuajes que se encontraban ocultos y aproximarnos a sus formas (Figs. 2, 4, 6 y 8).

Las zonas corporales que están cubiertas con diseños se presentan en la tabla № 2. Cabe señalar que la mayor representatividad de unas partes corporales sobre otras podría estar alterada por la falta de integridad de las momias, considerando que no todo el cuerpo se ha momificado ni todos los cuerpos están completos. En general se observa que existe una conservación diferencial, abundando las manos sobre otras partes corporales.

Tabla 2. Regiones corporales que presentan tatuajes, presentada por momia

\begin{tabular}{|c|c|c|c|c|c|c|c|c|c|c|c|c|c|c|}
\hline $\begin{array}{l}. \stackrel{\pi}{\Xi} \\
\stackrel{\Xi}{\Sigma}\end{array}$ & $\underset{\tilde{U}}{\tilde{U}}$ &  & 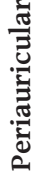 & $\begin{array}{l}\text { o } \\
\text { to } \\
\text { हี } \\
\text { : }\end{array}$ & 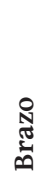 & 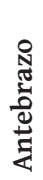 & 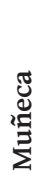 & 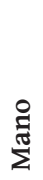 & 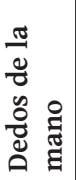 & $\frac{0}{\stackrel{n}{g}}$ & 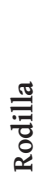 & $\frac{\mathbb{Z}}{0}$ & $\begin{array}{l}\circ \\
\stackrel{7}{\circ} \\
0\end{array}$ & $\stackrel{\oplus}{=}$ \\
\hline 12 & & & & & & & & $\mathrm{x}$ & $\mathrm{x}$ & & & & & \\
\hline 28 & & & & & & & & $\mathrm{x}$ & $\mathrm{x}$ & & & & & \\
\hline 30 & & & & & & & & $\mathrm{x}$ & & & & & & \\
\hline 70 & & & $\mathrm{X}$ & & $\mathrm{x}$ & $\mathrm{x}$ & & $\mathrm{x}$ & $\mathrm{x}$ & $\mathrm{x}$ & $\mathrm{x}$ & $\mathrm{x}$ & $\mathrm{x}$ & $\mathrm{x}$ \\
\hline 73 & $\mathrm{x}$ & & & & & $\mathrm{x}$ & $\mathrm{X}$ & $\mathrm{X}$ & $\mathrm{X}$ & & & & & \\
\hline 81 & $\mathrm{X}$ & $\mathrm{X}$ & & & & $\mathrm{x}$ & & & $\mathrm{x}$ & $\mathrm{x}$ & $\mathrm{X}$ & $\mathrm{x}$ & & \\
\hline 86 & & & & & & $\mathrm{X}$ & & $\mathrm{X}$ & $\mathrm{X}$ & & & & & \\
\hline 87 & & & & & X & $\mathrm{X}$ & & $\mathrm{X}$ & $\mathrm{x}$ & $\mathrm{X}$ & $\mathrm{x}$ & $\mathrm{X}$ & & \\
\hline 110 & & & & & & $\mathrm{x}$ & & $\mathrm{x}$ & & & $\mathrm{x}$ & $\mathrm{x}$ & & \\
\hline 234 & & & & & & $\mathrm{X}$ & $\mathrm{X}$ & $\mathrm{x}$ & $\mathrm{x}$ & & & $\mathrm{x}$ & & \\
\hline 437 & & & & $\mathrm{X}$ & $\mathrm{X}$ & $\mathrm{X}$ & $\mathrm{X}$ & $\mathrm{x}$ & $\mathrm{x}$ & $\mathrm{x}$ & $\mathrm{x}$ & $\mathrm{x}$ & & \\
\hline 451 & & & & & & & & & & & & & & \\
\hline
\end{tabular}

La mayoría de los diseños se disponen en los planos laterales y anteriores de los cuerpos (Figs. 9, $10,11)$, es decir que pudo ser visto por otros observadores que se encontraban frente o a un lado de los cuerpos tatuados. Las momias 73 y 81 presentan tatuajes en el rostro, mientras que la momia 70 tiene tatuajes circulares sobre la oreja (Fig. 12) y la momia 81 presenta diseños alrededor de las orejas (Fig. 13). El cuerpo con mayor superficie tatuada ha sido registrada en la momia 70, en la cual diseños ictiomorfos se presentan en todos los segmentos corporales a excepción de la cara y hombros.

Un número reducido de tatuajes se encuentran en zonas corporales que podrían haber estado cubiertas por vestimenta, asimismo se ha registrado la presencia de tatuajes en regiones corporales que podrían estar ocultas, tales como planos mediales, un ejemplo de ello es la presencia de tatuajes localizados entre las piernas de la momia 437 (Fig. 14), en la palma de la mano de la momia 73 (Fig. 15), en las regiones posteriores como la espalda y hombros de la momia (Fig. 17) e interdigitales (Figs. $15 \mathrm{y}$ 16), es decir en la superficie que existe entre los dedos. Dichas ubicaciones impedirían que los diseños tatuados sean vistos fácilmente por otros, sin embargo podrían ser exhibidos cuando el cuerpo se encontrara en movimiento y las zonas corporales tatuadas descubiertas de ropa.

La tabla № 3 muestra los quince diseños de tatuajes que han sido registrados. Los puntos sobre las manos son los diseños más frecuentes, presentándose generalmente en promedio dos puntos por 
cada dedo de la mano (Figs. 18, 19 y 20). Los diseños ictiomorfos son menos frecuentes, se han registrado sólo en las momias 70, 73 y 87, sin embargo han sido tatuados en todo el cuerpo de los individuos, cuya representación aglomerada parecen aludir a multiplicidad o abundancia (Figs. 21, 22 y 23). Como esquema constante, las representaciones ictiomorfas siempre muestran al pez con aletas y cola, similar a los diseños observados en la cerámica Paracas (Figs. 24 y 25).

Tabla 3. Tipos de diseños tatuados registrados mediante reflectografía infrarroja

\begin{tabular}{|c|c|c|c|c|c|c|c|c|c|c|c|c|c|c|c|c|}
\hline$\stackrel{\cdot \frac{\pi}{\Xi}}{\stackrel{0}{0}}$ & 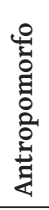 & 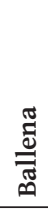 &  & $\frac{\mathscr{0}}{\tilde{D}}$ &  & 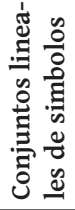 &  & 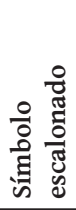 & 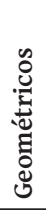 & 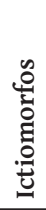 & 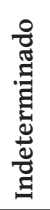 & 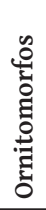 & 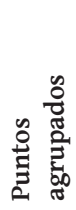 &  & 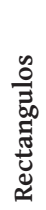 &  \\
\hline 12 & $\mathrm{X}$ & & $\mathrm{x}$ & & & & & & & & & & & $\mathrm{x}$ & & \\
\hline 28 & & & & & & $\mathrm{X}$ & & & & & & & & $\mathrm{X}$ & & \\
\hline 30 & & & & & & & & & & & & & & $\mathrm{x}$ & & \\
\hline 70 & & & & & & & & & & $\mathrm{x}$ & & & & & & \\
\hline 73 & & & & & & $\mathrm{x}$ & & & & $\mathrm{x}$ & & & $\mathrm{X}$ & $\mathrm{x}$ & $\mathrm{X}$ & \\
\hline 81 & & & & $\mathrm{x}$ & & & & & & & & $\mathrm{X}$ & & & $\mathrm{X}$ & $\mathrm{x}$ \\
\hline 86 & & & $\mathrm{X}$ & & $\mathrm{X}$ & & & $\mathrm{X}$ & & & & & & $\mathrm{X}$ & & \\
\hline 87 & & & & & & & & & & $\mathrm{x}$ & & & & & & \\
\hline 110 & & $\mathrm{x}$ ? & & & & $x$ & & & $\mathrm{x}$ & $\mathrm{x}$ & $\mathrm{x}$ & & & $\mathrm{x}$ & $\mathrm{x}$ & \\
\hline 234 & & & & & & $\mathrm{x}$ & & & & & & & $\mathrm{x}$ & & & \\
\hline 437 & & & $\mathrm{X}$ & & & $X$ & & & & $\mathrm{X}$ & & & $X$ & $X$ & & \\
\hline
\end{tabular}

El numero de momia se presenta según el numero de fardo asignado por Julio C. Tello (Tello y Mejía 1979)

Como patrón se observa que los puntos aparecen en el dorso de los dedos y manos, mientras que las bandas aparecen sólo en el dorso de las manos, lo cual se ha registrado en las momias 12, 86 y 437 (Figs. 26, 27 y 28). El símbolo escalonado ha sido registrado en el dorso de la mano de la momia 86, cuyo diseño también aparece en la cerámica Paracas (Figs. 29, 30 y 31). Diseños que podrían ser ornitomorfos son más escasos y se han encontrado en el antebrazo la momia 81 (Fig. 32).

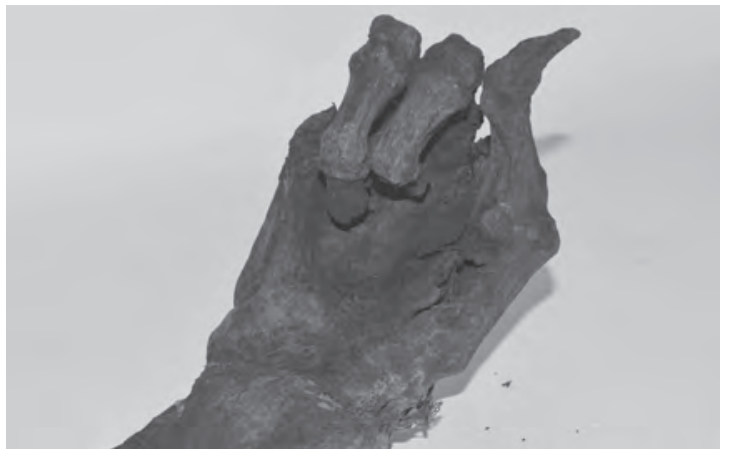

Figura 1. Mano derecha de la momia 110, imagen obtenida con cámara convencional. La mano presenta una coloración negruzca debido a la pintura negra utilizada en el tratamiento funerario. A simple vista no se observan tatuajes.

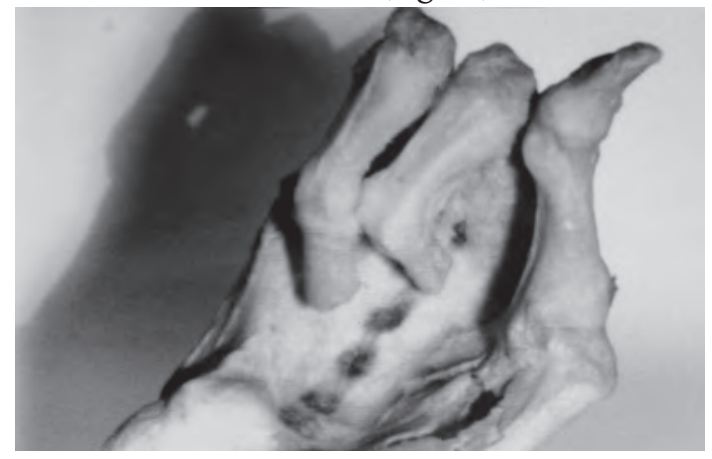

Figura 2. Mano derecha de la momia 110, imagen obtenida con reflectografía infrarroja. Se logra observar un tatuaje sobre el dorso de la mano. El diseño está compuesto por una serie de puntos alineados, al parecer interconectados por una franja muy sutil. 


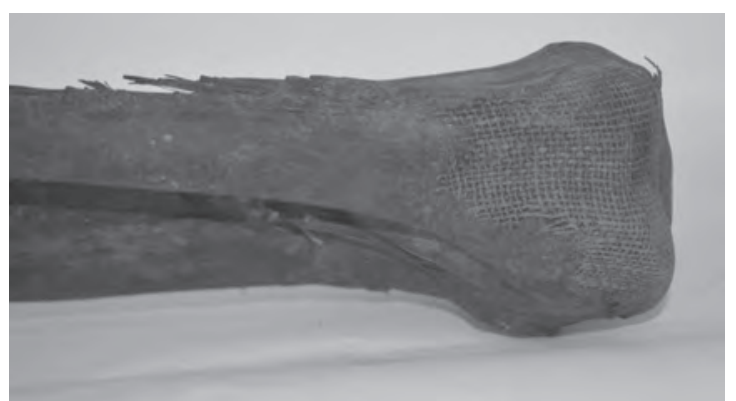

Figura 3. Muslo y pierna derecha de la momia 87, imagen obtenida con cámara convencional. Nótese el color negruzco de la superficie de la momia, debido a la colocación de pintura negra como parte del tratamiento funerario. No se observan tatuajes.



Figura 5. Mano izquierda de la momia 28, vista anterior, imagen obtenida con cámara convencional. No se observan tatuajes en la superficie debido a la coloración oscura de la piel.



Figura 7. Mano izquierda de la momia 30, imagen obtenida con cámara convencional. No se observan tatuajes en superficie. La coloración oscura de la piel momificada revela el tratamiento funerario.



Figura 4. Muslo y pierna derecha de la momia 87, imagen obtenida con reflectografía infrarroja. Se observan varios diseños ictiomorfos sobre el lado anterior del muslo y el lado posterior de la pierna.



Figura 6. Mano izquierda de la momia 28, imagen obtenida con reflectografía infrarroja. Se observan varios puntos tatuados sobre los dedos y palma, asi como líneas punteadas desde la muñeca hasta el antebrazo.

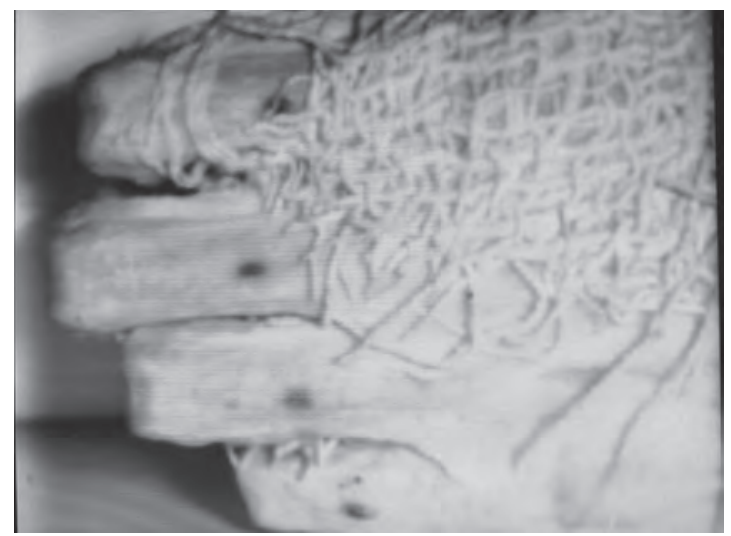

Figura 8. Mano izquierda de la momia 30, imagen obtenida con reflectografía infrarroja. Sobre cada uno de los dedos no cubiertos por el textil se pueden observar tatuajes de puntos. 


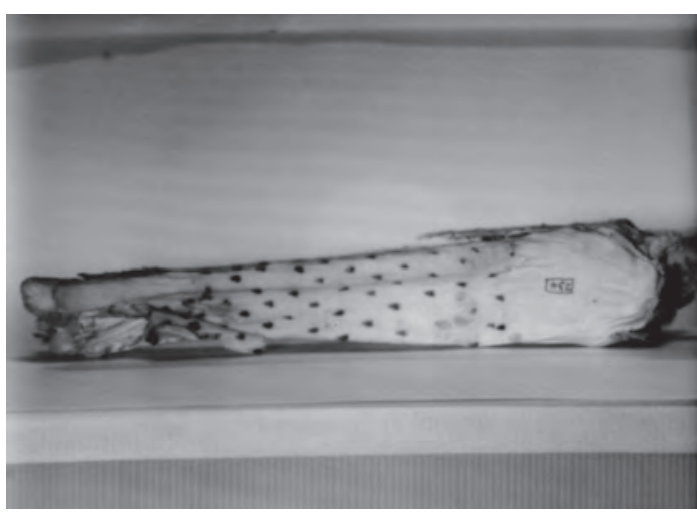

Figura 9. Pierna derecha de la momia 234, imagen obtenida con reflectografía infrarroja. Se observan múltiples diseños a manera de puntos agrupados que se distribuyen debajo de la rodilla hasta el tobillo.

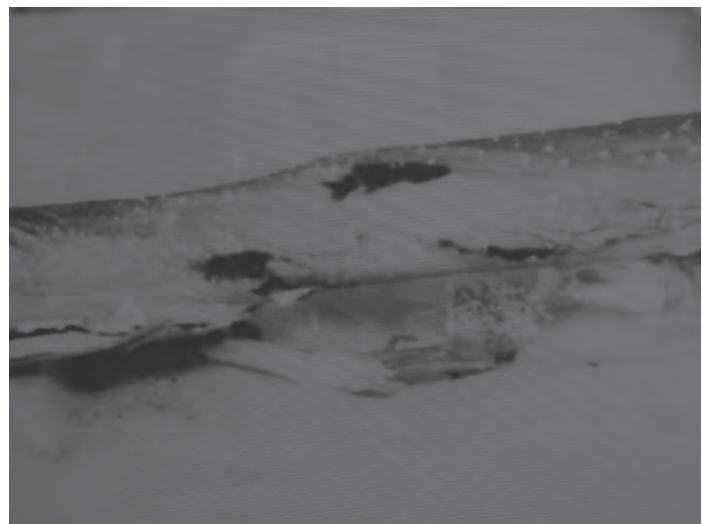

Figura 11. Brazo izquierdo de la momia 70, imagen obtenida con reflectografía infrarroja. Se observan tatuajes de diseños ictiomorfos.

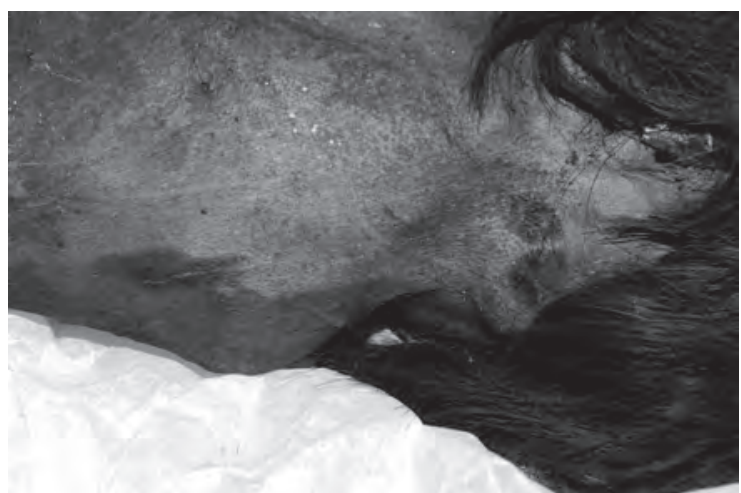

Figura 13. Vista lateral de la cabeza de la momia 81, imagen obtenida con cámara convencional. Se observa un tatuaje ictiomorfo. Sobre la oreja hay dos tatuajes, el superior es un círculo con punto concéntrico, mientras que el inferior es un circulo completo.

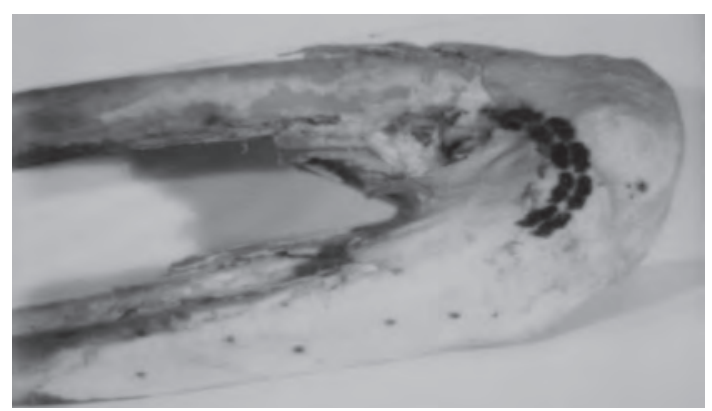

Figura 10. Pierna izquierda flexionada de la momia 437, imagen obtenida con reflectografía infrarroja. Se observa dos diseños de tatuajes. El primero de ellos un grupo de 12 diseños dispuestos en pares, de forma paralela, sobre la región lateral de la rodilla. En la pierna se observan tatuajes de puntos sobre la región anterior y lateral.

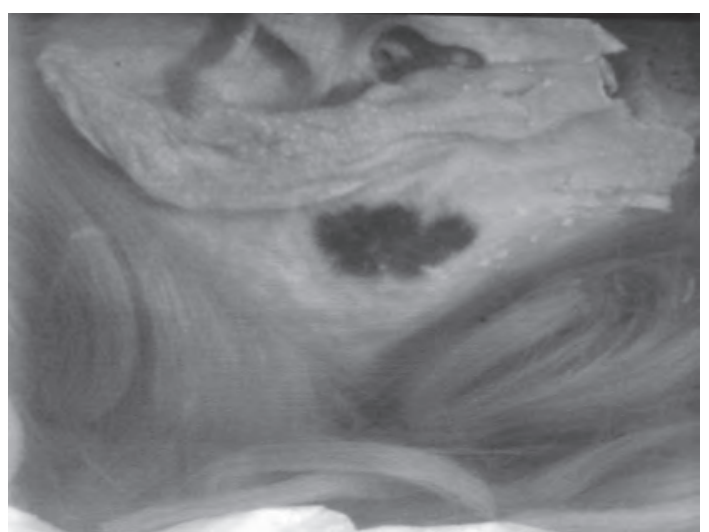

Figura 12. Tatuaje alrededor de la oreja derecha de la momia 70, imagen obtenida con reflectografía infrarroja.

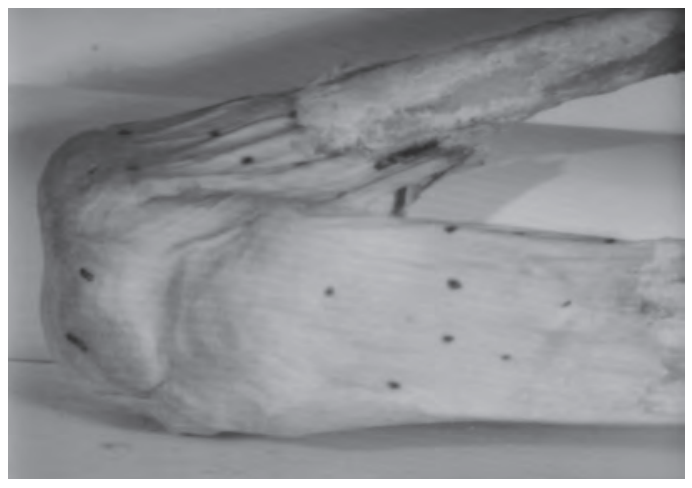

Figura 14. Pierna izquierda de la momia 437, imagen obtenida con reflectografía infrarroja. Obsérvese los tatuajes con diseños de puntos que se distribuyen en las regiones lateral y posterior del muslo, rodilla y pierna. 


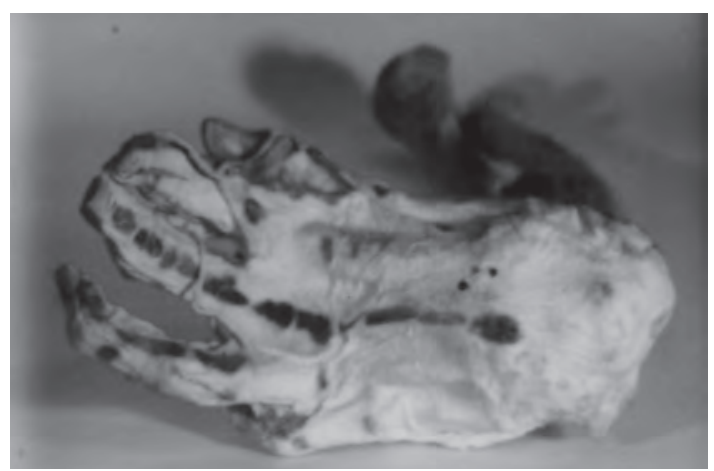

Figura 15. Mano izquierda de la momia 73, imagen obtenida con reflectografía infrarroja. Obsérvese el tatuaje manera de franjas ubicadas entre los dedos anular y medio.

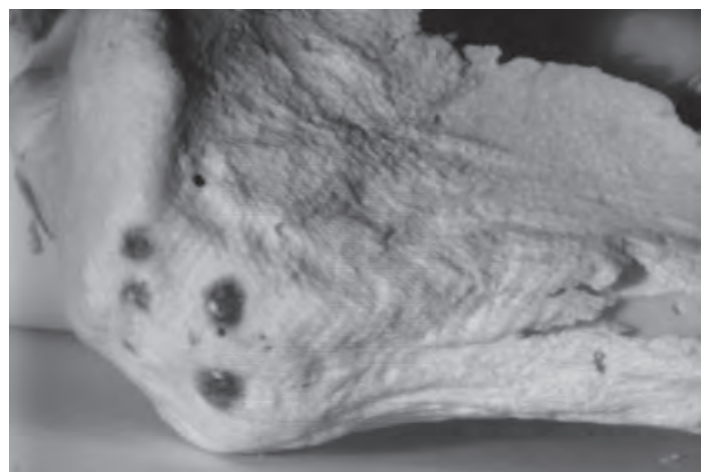

Figura 17. Hombro de la momia 437, imagen obtenida con reflectografía infrarroja. Se observa un grupo de puntos tatuados sobre el hombro, cubriendo parte de la región lateral y posterior.



Figura 19. Imagen dorsal de la mano izquierda, imagen obtenida con reflectografía infrarroja. Sobre los dedos, dorso de la mano y antebrazo se observan puntos tatuados. Sobre la superficie dorsal de cada dedo se observan dos puntos, mientras que entre los dedos meñique y anular se registra un punto tatuado por cada dedo.

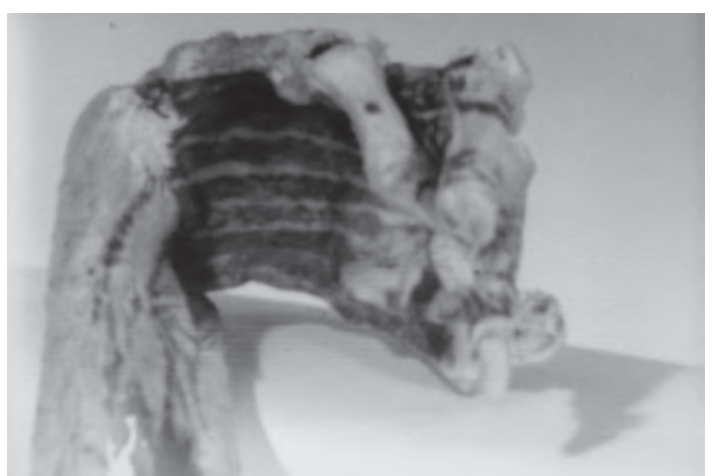

Figura 16. Mano izquierda de la momia 86, imagen obtenida con reflectografía infrarroja. Sobre la palma se observa un grupo de tatuajes a manera de franjas que cubren toda la superficie. También se observan puntos y franjas sobre los dedos y muñecas.

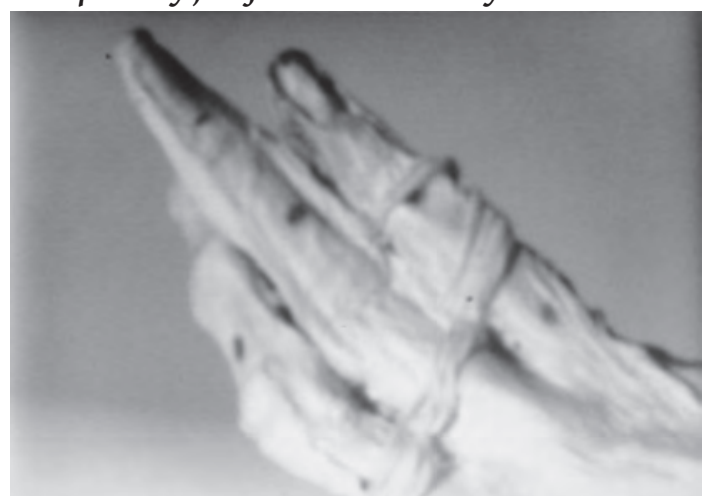

Figura 18. Mano izquierda de la momia 12, imagen obtenida con reflectografía infrarroja. Sobre la superficie dorsal se observa un grupo de puntos tatuados, dos puntos por cada dedo.

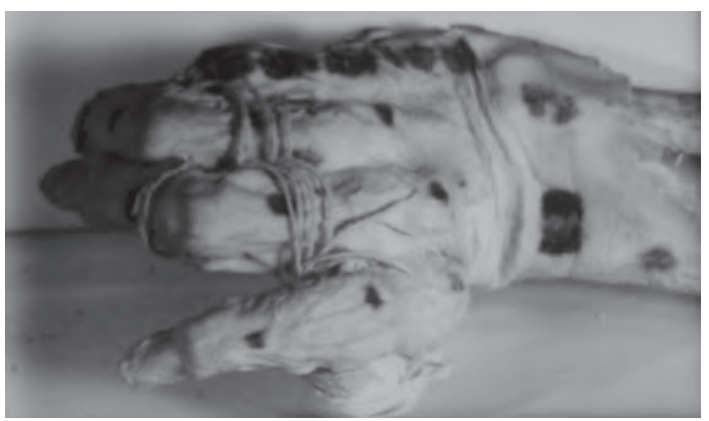

Figura 20. Imagen dorsal de la mano derecha de la momia 73, imagen obtenida con reflectografía infrarroja. La mano presenta diversos diseños tatuados. Sobre los dedos y el dorso de la mano se observan puntos tatuados, a razón de dos puntos por dedo. Asimismo existen diseños zoomorfos tatuados sobre la región medial de la mano, un rectángulo sobre la muñeca y puntos que llegan al antebrazo. 


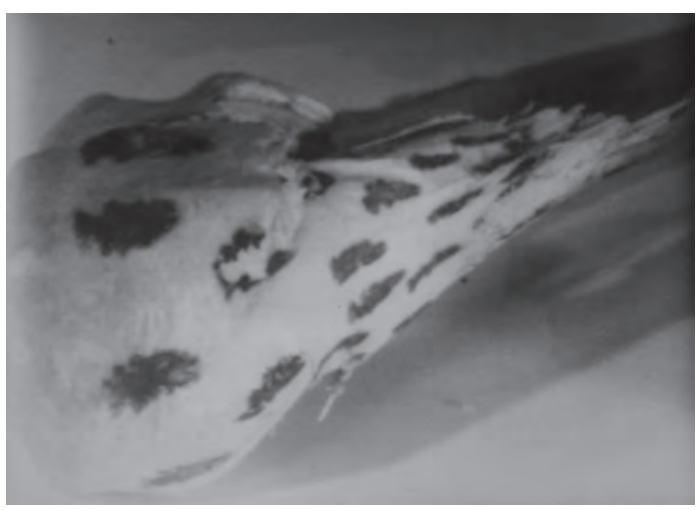

Figura 21. Muslo y rodilla derecha de la Momia 70, imagen obtenida con reflectografía infrarroja. Se observan varios diseños ictiomorfos tatuados sobre la región anterior, cubriendo la mayor parte de la superficie corporal.

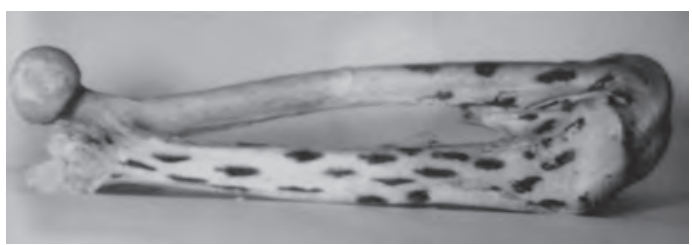

Figura 23. Muslo y pierna izquierda de la momia 87, imagen obtenida con reflectografía infrarroja. Sobre toda la superficie corporal se observan tatuajes que corresponden con diseños ictiomorfos. Los diseños se distribuyen sobre las regiones anterior, lateral, medial y posterior.

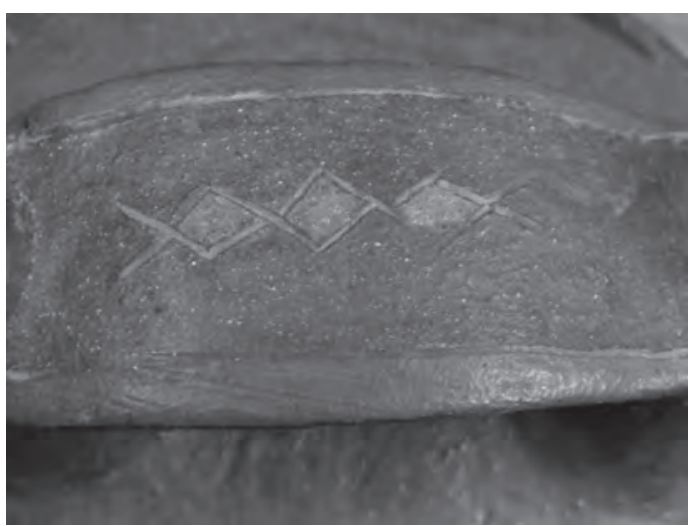

Figura 25. Detalle de diseños ictiomorfos sobre asa gollete de cerámica Paracas (C-16155). Colección del Museo Nacional de Arqueología, Antropología e Historia del Perú.

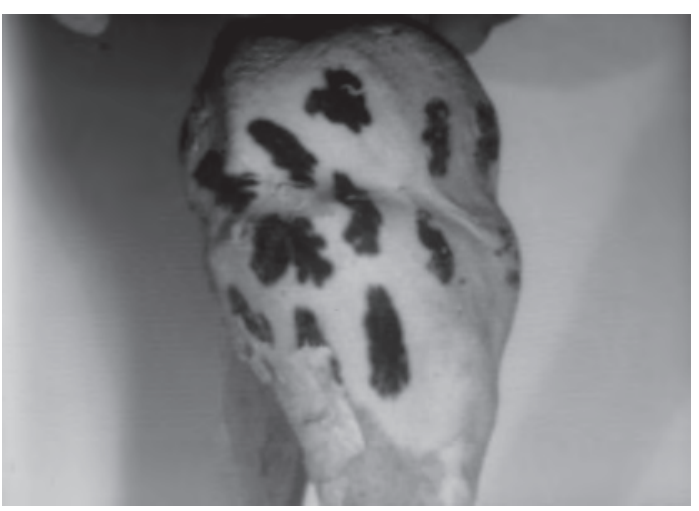

Figura 22. Rodilla y pierna izquierda de la momia 81, imagen obtenida con reflectografía infrarroja. Los tatuajes asemejan diseños ictiomorfos, cuyas formas se encuentran alteradas debido al proceso de momificación y consecuente contracción de tejidos.

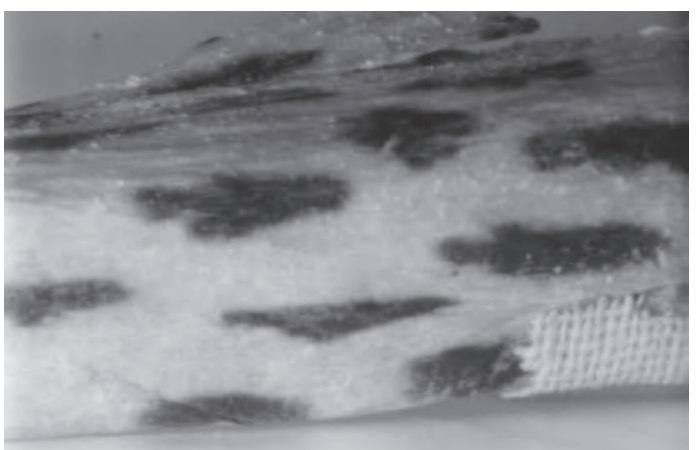

Figura 24. Detalle de tatuajes ictiomorfos sobre la pierna izquierda de la momia 87. Imagen obtenida con reflectografía infrarroja.

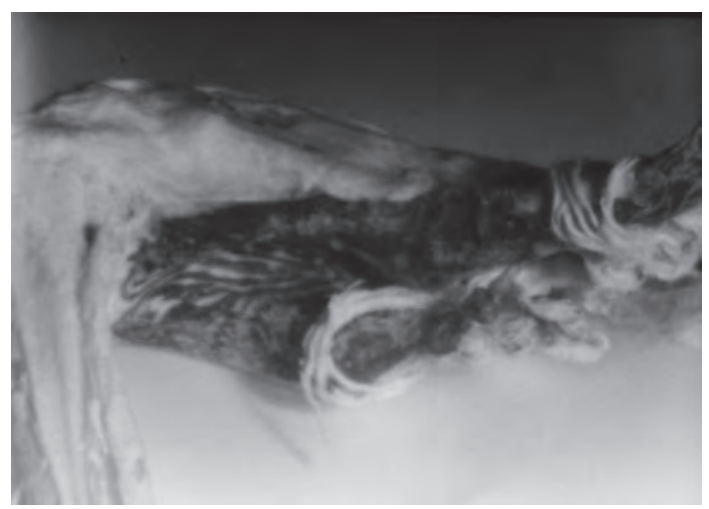

Figura 26. Mano derecha de la momia 12, imagen obtenida con reflectografía infrarroja. Se observan bandas gruesas tatuadas sobre las regiones lateral y dorsal de la mano. 


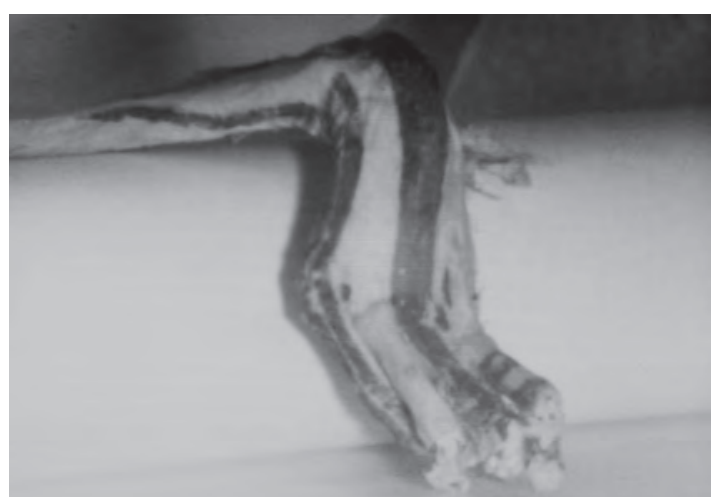

Figura 27. Mano derecha de la momia 86, imagen obtenida con reflectografía infrarroja. Se observan bandas gruesas tatuadas sobre el dorso de la mano y parte del antebrazo. Sobre los dedos se observan tatuajes anulares que circundan el diámetro de los dedos.

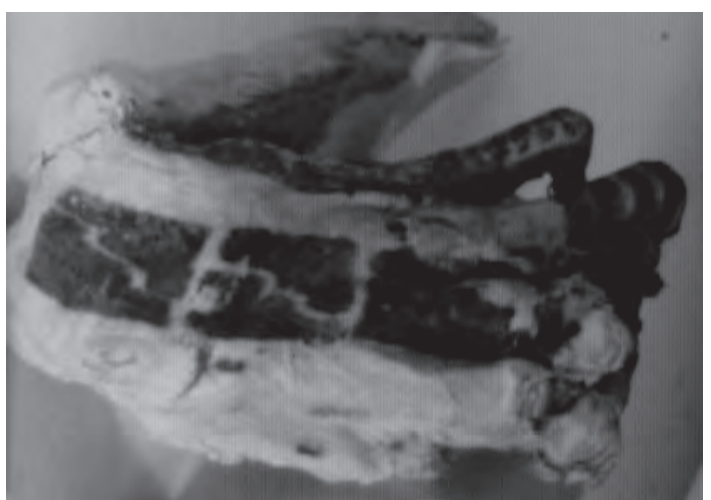

Figura 29. Símbolo escalonado sobre el dorso de la mano izquierda de la momia 86. Imagen obtenida con reflectografía infrarroja.

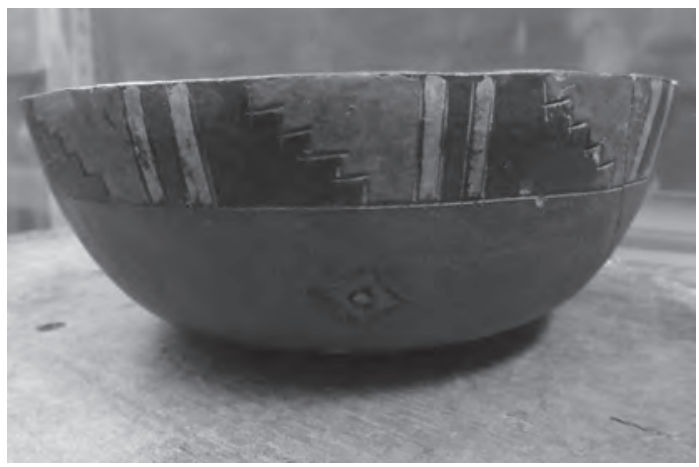

Figura 31. Cuenco Paracas que muestra el diseño escalonado (C-16155), similar al tatuaje observado en la mano derecha de la momia 86. Colección del Museo Nacional de Arqueología, Antropología e Historia del Perú.

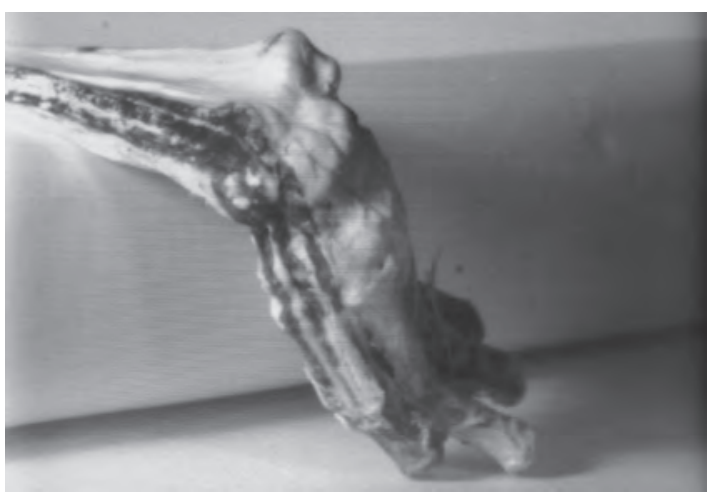

Figura 28. Mano derecha de la momia 437, imagen obtenida con reflectografía infrarroja. Se observan bandas gruesas, tatuadas en grupo de 3 que se distribuyen a lo largo de la mano y el antebrazo.

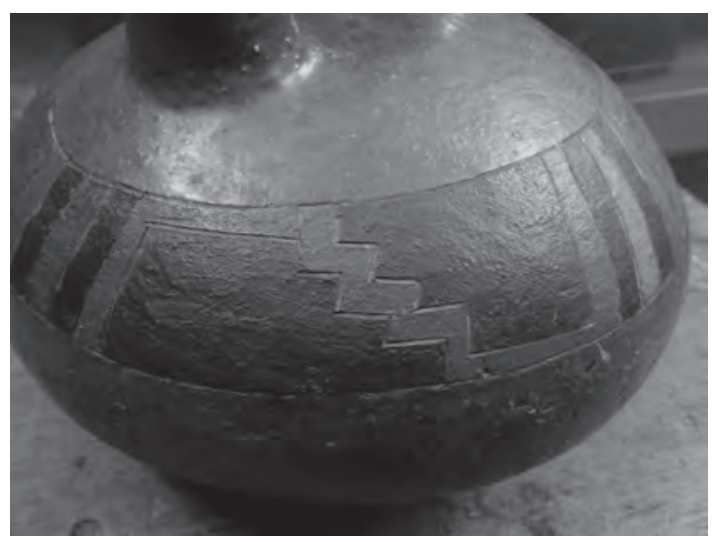

Figura 30. Cerámica Paracas que muestra el diseño escalonado (C-16155). Colección del Museo Nacional de Arqueología, Antropología e Historia del Perú.

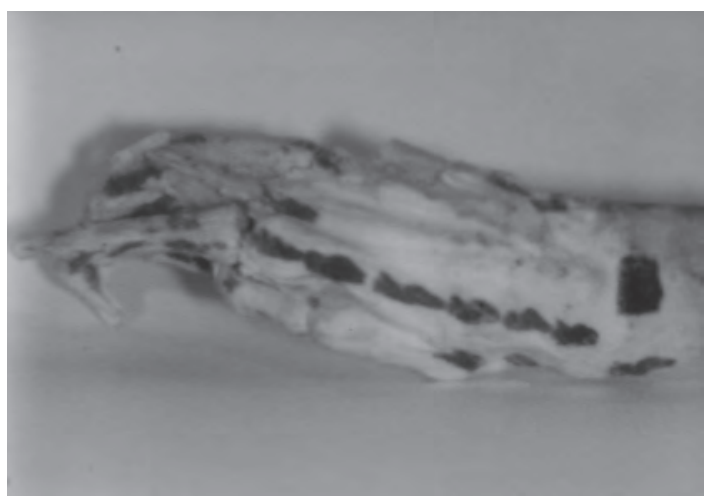

Figura 32. Mano derecha de la momia 73, imagen obtenida con reflectografía infrarroja. Se observa un grupo de tatuajes que asemejan ser diseños ictimorfos, dispuestos en hilera. 
Un único diseño antropomorfo se ha registrado en la palma de la mano de la momia 12, el cual corresponde con un ser con cara sonriente y cuatro apéndices, enmarcado por dos bandas anchas laterales (Fig. 33). Asimismo, un diseño cuyas características guarda similitud con lo que podría ser una orca se ha hallado en la rodilla de la pierna izquierda de la momia 110. Aunque el diseño está parcialmente cubierto por un textil llano (Fig. 34), se nota el parecido del trazo del tatuaje con el dibujo de la cabeza, hocico y aletas/patas de una orca que forma parte de un adorno colgante de cuero procedente de Paracas (Fig. 35).

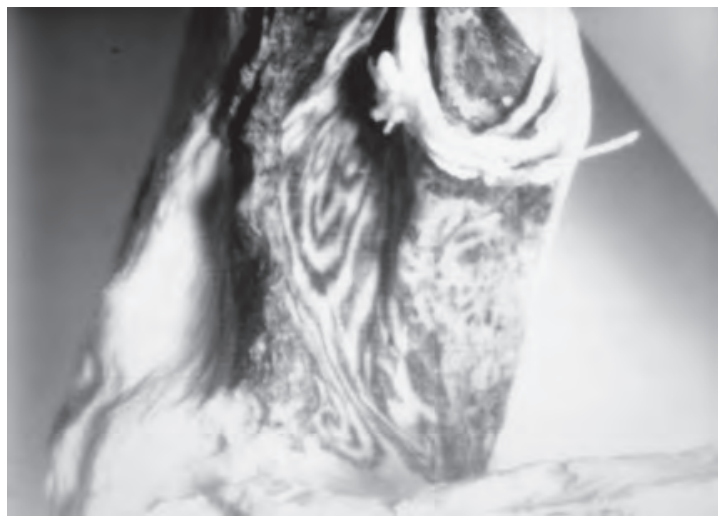

Figura 33. Mano derecha de la momia 12, imagen obtenida con reflectografía infrarroja. Se observa un tatuaje en la palma de la mano, el cual corresponde con un diseño antropomorfo con apéndices, presenta ojos, nariz y boca sonriente. El diseño se encuentra enmarcado por dos bandas paralelas.

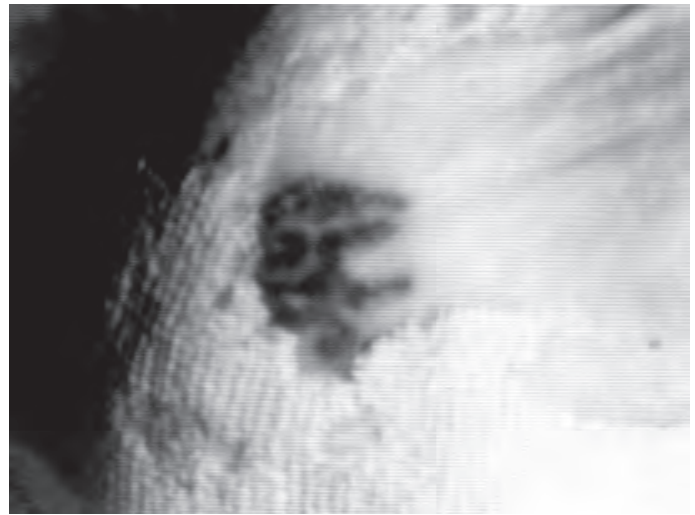

Figura 34. Rodilla izquierda de la momia 110, imagen obtenida con reflectografía infrarroja. El tatuaje está cubierto parcialmente por un textil. El diseño parece simular una cabeza con un ojo, posee un apéndice como boca que se conecta con la cabeza, además de dos apéndices que salen debajo de la cabeza a manera de patas o aletas. Se presume que podría ser una orca Paracas.

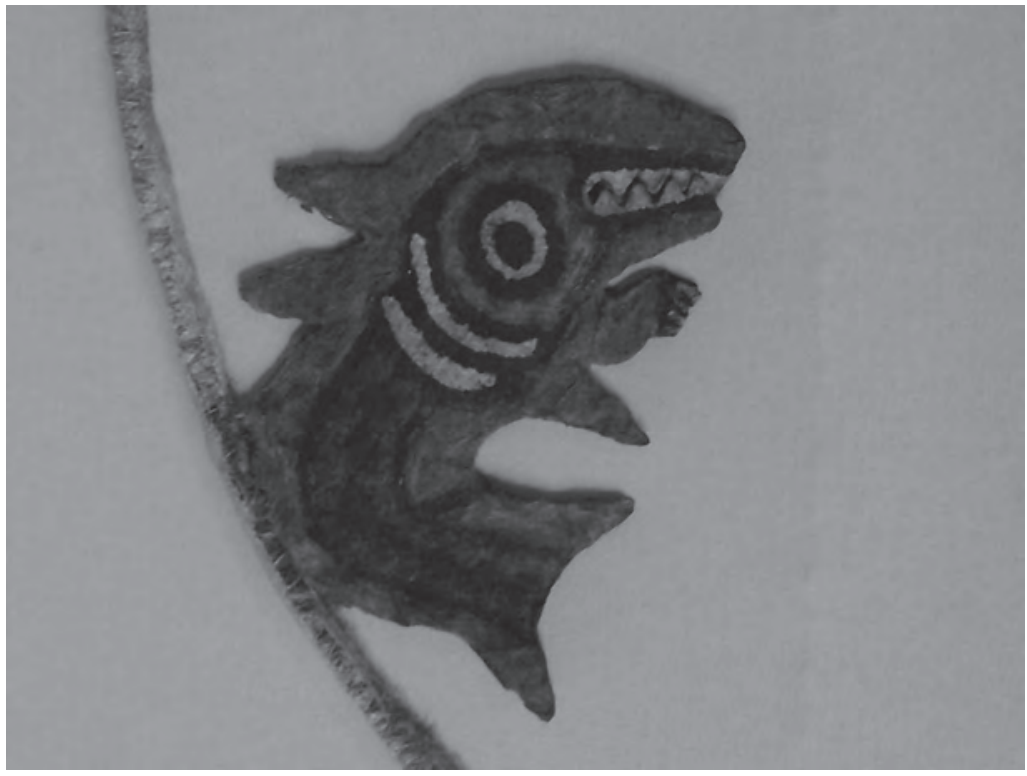

Figura 35. Detalle de una orca Paracas, soporte cuero pintado. Colección del Museo Nacional de Arqueología, Antropología e Historia del Perú. 


\section{Discusión}

La técnica de reflectografía infrarroja ha permitido observar tatuajes en momias Paracas-Necrópolis que se encontraban ocultos por el tratamiento funerario y aquellos cuyos diseños no podían ser definidos debido a procesos avanzados de deterioro. Los resultados demuestran que los cuerpos llevan símbolos tatuados sobre la piel como mensajes permanentes, destacando el papel del cuerpo como lugar de exhibición y comunicación.

Existe una amplia gama de posibles motivaciones detrás de los diseños seleccionados por los individuos Paracas para decorar el cuerpo y su representación a través de símbolos. Aunque los significados y mensajes de los tatuajes Paracas- Necrópolis se hayan perdido en el tiempo, es indiscutible que los cuerpos han sido utilizados como herramientas comunicativas, retratando identidades e inscribiendo significados. Es notorio que varios de los diseños tatuados que se han registrado en las momias Paracas-Necrópolis se presenten también en textiles y cerámica de prestigio Paracas, lo que nos lleva a suponer que los diseños tatuados fueron marcadores de prestigio, transcribiendo a su vez datos de la organización social y religiosa en los cuerpos, simbolizando el prestigio y el estatus de un individuo frente a los restantes.

La visibilidad o localización de los tatuajes, sumado a las modificaciones muy marcadas del cráneo, demostraría la importancia del cuerpo para exhibir y comunicar, tal vez la inclusión o exclusión social, el poder, la pertenencia o el estatus. La mayor parte de los cuerpos analizados corresponden a individuos femeninos (Tabla 1). La presencia de tatuajes corporalmente extensos, ricos en iconografia, sobre los cuerpos de mujeres Paracas, podría tener relación con su participación en estructuras de prestigio, posiblemente política. El rango alto que pudieron haber poseído, es también expresado a través de la ornamentación corporal y el ajuar funerario rico en indumentaria personal.

\section{Agradecimientos}

El Dr. Jaime Mariazza Foy nos brindó las facilidades para el uso del equipo de reflectografía infrarroja en el Museo Nacional de Arqueología, Antropología e Historia del Perú. Durante los análisis contamos con la colaboración de los conservadores Luis Sandoval y Jesús Calderón del Laboratorio de Conservación y Restauración del MNAAHP. Las fotografías fueron tomadas por Rosario Jhong y Luis Sandoval. A todos ellos va nuestro agradecimiento por su compañía y apoyo profesional. 


\section{BiBLIOGRAFÍA}

ALLISON M, J.; L. LINDBERH, C. SANTORO y G. FOCACI

1978 «Tatuajes y pintura corporal de indígenas de Peru y Chile». Chungará 7: 218-237. Arica: Universidad de Tarapacá, Facultad de Ciencias Sociales y Jurídicas, Departamento de Antropología.

AUFDERHEIDE, A. y Conrado RODRIGUEZ-MARTIN

1998 The Cambridge Encyclopedia of Human Paleopathology. Cambridge: Cambridge University Press.

BRAIN, Robert

1979 The decorated body. Londres: Hutchinson.

DEMBO, Adolfo y Jose IMBELLONI

1938 Deformaciones intencionales del cuerpo de carácter étnico. Buenos Aires: J. Anesi.

DREWAL, Henry y Margareth Thompson

1983 Gelede: art and females power among the Yoruba. Bloomington: Indiana University Press.

FARIS, James C.

1972 Nuba personal art, Londres: Duckworth.

FIELD, Henry

1958 «Body-marking inSouth-western Asis», Cambridge, Peabody Museum of Archaeology and Ethnology, Harvard University, vol. XLV, 1.

HANDY, Willowdean C

1922 «Tattooing in the Marquesas», Bulletin of the Bernice P. Bishop Museum, krauss reprint, 1971.

HOROWITZ, Donald L.

1985 Ethnic Groups in Conflict. Berkeley: University of California Press.

SOROKIN, Pitrim A.

1973 Sociedad, cultura y personalidad, Madrid: Aguilar.

STEWART, T. D.

1943 «Skeletal remains from Paracas, Peru». American Journal of Physical Anthropology, 1: 47-63.

TELLO, Julio C.

1959 Paracas: Primera parte. Lima: Institute of Andean Research.

TELLO, Julio C. y Toribio MEJÍA

1979 Paracas, segunda parte: Cavernas y Necrópolis. Universidad Nacional Mayor de San Marcos y Institute of Andean Research: Lima. Tylor, E.B.

VAN ASPEREN DE BOER, J.R.J.

1976 «An introduction to the scientific examination of paintings». En J. van Asperen y J. Filedt (eds.), Scientific examination of early Netherlandish Painting, Bussum: 1-40.

1998 «Some Reflections upon the Impact of Scientific Examination on Art Historical Research». En E. Hermens (ed.), Looking through paintings, Baarn, London: 13-17

VREELAND, James M.

1976 Informe sobre la diseccion, análisis y estudio inicial del fardo funerario № 226 de ParacasNecrópolis, del Perú, desenfardelado en Agosto de 1975. 